\title{
The role of albedo and contrast in a test of selective attention ${ }^{1}$
}

\author{
P. M. MCDONNELL ${ }^{2}$ \\ UNIVERSITY OF TORONTO
}

The operation of a selective process was demonstrated under conditions that eliminated exploratory behavior, receptor adjustments, and that could not be construed as abstraction. Ss were given a choice reaction-time test to tachistoscopically exposed stimuli. There were three conditions of brightness and contrast. Four targets equally spaced in brightness units were presented either on a black, a medium gray, or a white background. If a selective process was found to operate, it was hoped to separate the effects of albedo and contrast as factors determining priority in selection. The results confirmed that $S$ s chose the stimuli of highest contrast, but in the event that contrast was equivalent for two stimuli, the target of highest albedo was chosen significantly more often.

Berlyne (1969) has pointed out that the term selective attention has been used to cover a wide range of selective phenomena. On the one hand, there is selection of attributes, or properties belonging to the same region of the stimulus field. This form of selective behavior might well be termed abstraction and is best exemplified by experiments on reversal discrimination problems (MacKintosh, 1965) and by experiments on problem solving (Bower \& Trabasso, 1964). On the other hand, there is selection by exploratory behavior that involves variously, locomotor activity, receptor adjustments, and changes in the sensitivity of the receptors. All of these changes serve to increase the flow of information from a particular source in the environment. The term attention has often been applied to experiments that measured the direction and intensity of exploratory behavior, i. e., Brandt (1940), Dember and Earl (1957), Egeth (1967), Lawson, Goldberg, and Rausch (1967).

Still another form of selectivity in behavior involves rejection of information by the operation of central processes. This form of selectivity operates independently of the receptor organs and occurs when two or more afferent processes compete or interact at a point in the nervous system beyond the receptor cells. Thus there is no possibility that one process will predominate because it is moved to the center of the sensory channel. This form of selectivity is exemplified in a number of different experimental situations such as dichotic and binaural listening (Broadbent, 1958; Triesman \& Geffen, 1967), studies on the psychological refractory period (Smith, 1967), studies on visual and auditory masking (Raab, 1963), and finally studies on binocular rivalry (Levelt, 1968). The problem is that in most of these studies it is not possible to conclude that selectivity in behavior was independent of exploratory activity or receptor adjustments; that it was due to the operation of a central selective process. In dichotic listening studies, for example, the stimulus material has often been verbal, which would require analysis of semantic content. Also responses were often given after a delay of a few seconds. Consequently the selectivity may have been affected seriously by other internal neural processes or memorial processes that supplement the basic selective mechanism.

What is required is a demonstration of a central selective process in performance distinct from exploratory responses, orienting responses, and abstraction. To accomplish this task, it is necessary to eliminate head and eye movements, to present competing stimuli in equally sensitive positions in the sensory channel, and to use simple targets and direct response measures.

In the following experiment each stimulus was associated with a corresponding response but only one response could be performed. While the choice was free, the Ss were told that the task was a test of reaction time, and they were instructed to choose and respond as quickly as possible. All targets were exposed for a duration of $0.1 \mathrm{sec}$, which, according to Riggs, Armington, and Ratliff (1954), should have been too brief for the Ss' gaze to drift from the fixation point to one of the stimuli before the exposure ended. It also should have been well below the reaction time for voluntary saccadic eye movements (Bartz, 1962). Thus any systematic selection of targets should be independent of the effects of receptor adjustments.

Berlyne (1969), Broadbent (1958), and Sanders (1967) have all stressed that certain classes of stimulus events have a high probability of being selected. Most agree that stimulus intensity is one such property but it is not clear whether priority in selection results from the absolute intensity of the stimulus (albedo) or the greater distinctiveness that results from contrast with the background. It was therefore necessary to separate albedo and contrast experimentally. Four targets equally spaced in subjective brightness were presented on three different backgrounds: a black background, an intermediate gray, and a white background. On the gray background, degree of contrast is constant for the highest and lowest albedos. On a white background, the variables, albedo and contrast ought to be experimentally separable, i.e., as albedo increases, contrast necessarily decreases. Finally, on a black ground, selection of the target of highest albedo or highest contrast would mean selecting the same target so the variables are experimentally confounded.

\section{Subjects}

\section{METHOD}

Thirty Ss were used for each background condition. All Ss were first-or second-year undergraduates in psychology courses at the University of Toronto. Each group consisted of equal numbers of males and females.

\section{Apparatus}

A Gerbrands two-channel tachistoscope was used to present targets. Measurements were made of field luminance for each background condition. The values in $\mathrm{fL}$ were: white, 5.06 ; gray, 2.38 ; black, 0.39 .

A Metrix type MDPR timer controlled the 4-sec exposure of the fixation field. The test-field exposure duration of $0.1 \mathrm{sec}$ was automatically controlled by a Hunter timer, type $100 \mathrm{C}$.

The $E$ presented the fixation field manually, but the test field was automatically illuminated at the offset of the Metrix timer. When the Hunter timer timed out, the test-field lamp was extinguished and both fields were dark between trials.

Four keys were arranged in a diamond-shaped pattern on the panel to correspond to the positions of targets in the tachistoscope. A fifth key was positioned at the center of the panel for the $S$ to rest his finger on between trials. Since the keys were under the tachistoscope, the Ss could not see them and had to learn their location by feel.

Onset of the Hunter timer sent a pulse to a Hunter Klockounter that timed until 
the $\mathbf{S}$ depressed one of the four keys. The Klockounter recorded elapsed time in msec.

The stimuli were circles cut from neutral painted Colormatch papers. All circles were $2 \mathrm{in}$. in diam and subtended a visual angle of $2 \mathrm{deg} 36 \mathrm{sec}$ of arc. No part of any target fell within the fovea as their centers were located $3 \mathrm{deg} 54 \mathrm{sec}$ from the visual center of the field.

In a preliminary experiment, five Ss matched 10 shades of neutral Colormatch papers with a standard chart of neutral Munsell values. From the Colormatch samples, five were chosen that were judged equivalent to the Munsell values of 3.0 , $4.0,5.0,6.0$, and 7.0. The midgray background paper matched the Munsell value of 5.0. The other two background values were equivalent to Munsell values of 1.0 (black) and 9.5 (white). A small red dot was used as a fixation point and was mounted on either a black, gray, or white background depending on the condition.

\section{Procedure}

Each $\mathrm{S}$ was given a randomized sequence of 48 trials, consisting of 16 single targets, 16 paired targets, and 16 quadruple targets. On single trials, each of the four albedos $(3.0,4.0,6.0,7.0)$ appeared four tinnes at each of the corners of the diamond. The pairs consisted of eight high separation pairs (Munsell values 3 and 7 ) and eight low separation pairs (Munsell values 4 and 6 ) in different combinations of locations. On quadruple trials, all four albedos appeared simultaneously but in 16 different permutations of locations.

Ss were instructed to fixate the red dot in the center of the field and, when the targets appeared, to choose one and react as quickly as possible. It was stressed that only one key could be pressed on each trial but that there were no right or wrong choices.

\section{RESULTS}

The choice data refer only to paired and quadruple stimulus presentations. The double choices were analyzed using a $t$ test for paired observations, whereas the quadruples were subjected to a nonparametric trend analysis described by Ferguson (1965).

The mean numbers of responses made to each stimulus of the high separation pairs, the low separation pairs, and the quadruples are presented in Table 1. Table 2 summarizes the results of statistical tests performed on the paired data of Table 1.

As far as the paired presentations are concerned, Ss significantly of ten chose the lighter stimuli ( 3 and 4 ) on the black and middle gray backgrounds and the darker

Table 1

Mean Number of Choice Responses. The means for the pairs are out of a possible maximum of 8.0 and for the quadruples are out of a possible maximum of 16.0

\begin{tabular}{|c|c|c|c|c|c|c|c|c|c|}
\hline \multicolumn{2}{|c|}{$\begin{array}{l}\text { Type of Trial } \\
\text { Munsell Value }\end{array}$} & \multicolumn{2}{|c|}{ High Contrast } & \multicolumn{2}{|c|}{ Low Contrast } & \multicolumn{4}{|c|}{ Quadruples } \\
\hline $\begin{array}{l}\text { Mun } \\
\text { Back- } \\
\text { ground }\end{array}$ & $\begin{array}{l}\text { ell Value } \\
\text { No. } \\
\text { of Ss }\end{array}$ & 3 & 7 & 4 & 6 & 3 & 4 & 6 & 7 \\
\hline Black & 29 & 3.1 & 4.5 & 3.2 & 4.0 & 3.4 & 3.3 & 4.4 & 4.9 \\
\hline Gray & 28 & 2.6 & 5.0 & 3.0 & 4.2 & 4.0 & 3.4 & 4.3 & 4.3 \\
\hline White & 26 & 4.7 & 2.8 & 4.2 & 3.3 & 5.4 & 4.4 & 3.1 & 3.1 \\
\hline
\end{tabular}

stimulus (7.0) on the white background for the high separation targets. The $t$ value for the low separation pair (4.0 and 6.0) failed to reach significance.

Analysis of the data from quadruple stimuli presentations was done with a nonparametric trend analysis for several reasons. The distribution of choices over the four targets would be seriously distorted by virtue of the fact that choice of one target automatically lowered the number of times the others could be chosen. Also there was no way of knowing whether or not the albedo vaiues were, in fact, equally spaced.

Significant monotonic trends were found for both the black and white background conditions with $\mathrm{Z}$ scores of 2.96 and 3.73 , respectively, which were significant with $p<.01$. It can be determined from the means in Table 1 the trend is a rising one for stimuli on the white background. Nonsignificant monotonic, bitonic, and tritonic trends were found for the data on the gray background.

\section{DISCUSSION}

The results in the white background condition clearly support the conclusion that stimulus contrast predominates in Ss' choices over stimulus albedo. Only in this condition are albedo and contrast completely unconfounded. The results in the gray background condition suggest that when degree of contrast is equal Ss choose, and, presumably, attend to the stimulus of highest albedo value. If contrast was the sole factor in determining choices then targets of low and high albedo would have been selected equally often on a medium gray background.

The black background produces the expected result; the target of highest albedo (and contrast) was typically selected. These results confirm earlier findings by Berlyne (1950). It was also expected that the combined effect of both variables, albedo and contrast, might have produced a stronger effect, but the difference of the pair means was smallest for the black background condition. The distribution of free choices on quadruple targets indicates that degree of contrast and frequency of choice are directly and
Table 2

Obtained t-Values for Mean Differences of Selection Within High and Low Contrast Pairs. The tests for the black and white groups were one-tailed; the tests for the gray group were two-tailed.

\begin{tabular}{lll}
\hline & Pairs & \multicolumn{2}{c}{ Degree of Separation } \\
Bround & High & Low \\
\hline Black & $2.60^{* *}$ & $1.77^{*}$ \\
Gray & $4.78^{* *}$ & $2.19^{*}$ \\
White & $2.76^{* *}$ & $1.51 \mathrm{NS}$ \\
\hline
\end{tabular}

* $p<.05 ; * * p<.01 ; * * * p<.001 ; N S=$ not significant.

monotonically related. On both the black and white background, as contrast increases the mean number of choices is seen to increase.

Finally, the choice data give clear evidence that selectivity in attention can occur during tachistoscopic exposures and show that eye movements or other exploratory responses cannot be called upon to explain the direction of attention in this situation. A strong effect was obtained whether two or four stimuli appeared, so increasing the number of equivocal choices did not appear to increase or decrease the tendency to be selective.

While Broadbent's (1958) theory assumes that filtering can occur in Ss with fixed and steady receptors, there has been, to date, no clear evidence to support this position. Many of the auditory multichannel listening studies could be explained on the basis of differential effects during retention. The present experiment overcomes some of these difficulties by using simple physical stimuli and an immediate response measure.

\section{REFERENCES}

BARTZ, A. E. Eye movement latency, duration, and response time as a function of angular displacement. Journal of Experimental Psychology, 1962, 64, 318-324.

BERLYNE, D. E. Stimulus intensity and attention in relation to learning theory. Quarterly Journal of Experimental Psychology, 1950, 2, 71-75.

BERLYNE, D. E. Attention as a problem in behavior theory. In $D$. Mostofsky (Ed.), $A t t e n t i o n$. $\quad \mathrm{N}$ e w Y $\mathrm{Y} \circ \mathrm{r}$ : Appleton-Century-Crofts, 1969, (in press).

BOWER, G., \& TRABASSO, T. Concept identification. In R. C. Atkinson (Ed.), Studies in mathematical psychology. Stanford: Stanford University Press, 1964. Pp. 32-96. 
BRANDT, H. F. Ocular pattern as an index of the attentional value of size. American Journal of Psychology, 1940, 53, 564-571.

BROADBENT, D. E. Perception and communication. London: Pergamon Press, 1958.

DEMBER, W. N., \& EARL, R. W. Analysis of exploratory, manipulatory and curiosity behaviors. Psychological Review, 1957, 64, 91-96.

EGETH, H. Selective attention. Psychological Bulletin, 1967, 67, 41-57.

FERGUSON, G. A. Nonparametric trend analysis. Montreal: McGill University Press, 1965.

LAWSON, M., GOLDBERG, S., \& RAUSCH, M. Attention distribution as a function of novelty and familiarity. Psychonomic Science, 1967, 7, 227-228.
LEVELT, W. I. On binocular rivalry. The Hague: Mouton, 1968.

MacKINTOSH, N. J. Selective attention in animal discrimination learning. Psychological Bulletin, $1965,64,124-150$.

RAAB, D. Backward masking. Psychological Bulletin, 1963, 60, 118-129.

RIGGS, L. A., ARMINGTON, J. C., \& RATLIFF, F. Motions of the retinal image during fixation. Journal of the Optical Society of America, 1954, 44, 315-321.

SANDERS, A. F. The selective process in the function visual field. A report of the Institute for Perception R.V.O.:-T.N.O. Soesterberg, The Netherlands: Van Gorcum, 1963.

SMITH, Marilyn C. Theories of the psychological refractory period. Psychological Bulletin, $1967,67,202-213$.

TREISMAN, A., \& GEFFEN, G. Selective attention: Perception or response? The Quarterly Journal of Experimental Psychology, 1967, 19, 1-17.

\section{NOTES}

1. This study is based upon a dissertation submitted to the University of Toronto in partial fulfilment of the requirements for the $P h D$ degree. The writer would like to express particular appreciation to D. E. Berlyne for his supervision and helpful advice. The research was supported by a grant of the Ontario Institute for Studics in Education and by a grant from the National Research Council of Canada (APB-73) awarded to D. E. Berlyne.

2. Address: Department of Psychology, University of New Brunswick, Fredericton, N. B., Canada.

(Accepted for publication November 14, 1969.) 